\title{
Survey of Attitudes on Professionalism in Plastic and Reconstructive Surgery
}

\author{
Jin Yong Kim, Seok Joo Kang, Jin Woo Kim, Young Hwan Kim, Hook Sun \\ Department of Plastic and Reconstructive Surgery, Inje University Busan Paik Hospital, Inje University College of Medicine, Busan, Korea
}

Background The purpose of this study is to analyze the current attitudes toward professionalism, the core values, and the type of professionalism among plastic surgeons in Korea to establish a code of ethics regarding the role of professionalism for plastic and reconstructive surgeons.

Methods From March 9, to July 1, 2012, face-to-face and mail surveys were conducted targeting the 325 participants (256 specialists and 69 residents) who are registered members of the Korean Society of Plastic and Reconstructive Surgeons. The proportion of each response given to an item was obtained through statistical processing through frequency analysis. The Mann-Whitney $\mathrm{U}$ test was used to compare the differences in the responses between the resident group and the specialist group.

Results The survey results on the perception of professionalism in plastic surgery showed that a high proportion (90.5\%) of the respondents viewed the future of plastic surgeons as bright. Through evaluation of the importance of the value items,"professional dominance" (4.58 pts), "autonomy" (4.45 pts), "lifestyle" (4.34 pts), and "commercialism" (4.31 pts) were assessed as critical values. "Altruism" (3.84 pts), "interpersonal competence" (3.79 pts), and "social justice" (3.61 pts) were viewed as lesser values. This difference showed the characteristics of an entrepreneurial outlook.

Conclusions Plastic surgeons should pursue excellence, humanism, accountability, and altruism in order to overcome the crisis of professionalism in plastic surgery. In order to develop the necessary competencies of professionals, vocational education should be arranged by the Korean Society of Plastic Surgeons, and an appropriate code of ethics should be established.

Keywords Code of ethics / Plastic surgery / Professional role
Correspondence: Hook Sun Department of Plastic and Reconstructive Surgery, Inje University Busan Paik Hospital, Inje University College of Medicine, 75 Bokji-ro, Busanjin-gu, Busan 614-735, Korea Tel: +82-51-890-6236

Fax: +82-51-894-7976

E-mail:sun443@naver.com
No potential conflict of interest relevant to this article was reported.

\section{INTRODUCTION}

Doctors in Western society have formed their identify by establishing standards of professionalism. These regulations on appropriate conduct and ethical values and norms have been the basis for researchers to qualitatively differentiate medical professionals as a group $[1,2]$. As a result, those in medicine have been granted privileges such as autonomy and social prestige. However, in return, expectations of altruistic service to society have developed [3]. In the case of the American Society of Plastic Surgeons (ASPS), the Code of Ethics of the ASPS was formed, to guide the conduct of its members to act in accordance with the general and specific principles of the ASPS code of ethics, which pertains to contact with patients, peers, and the general 
public [4]. However, in the beginning of the 1960s, skepticism and criticism increased toward the conduct of physicians. Many held views that some doctors were using their autonomy only to advance their own interests and wrongly covering-up the unethical behavior of colleagues, putting collegiality before the interests of society [5]. This era was deemed a "crisis of professionalism," prompting self-reflection in the field of medicine.

The introduction of a licensing system for physicians in Korea was the result of the modernization of the health care system. The social status of doctors in Korea was not acquired through their own competition and quality management, but through the Korean government's unilateral introduction of a licensing system [6,7]. Historically, doctors in Korea did not have autonomy in establishing their role as health care professionals [8]. This phenomenon was also true among plastic surgeons. In 1973, the Korean government promulgated revised "Enforcement Regulations for Medical Law" due to the increasing number of plastic surgery patients. As a result, plastic and reconstructive surgery was recognized as a separate medical department, and residency programs were established. Since 1975, the Korean Society of Plastic and Reconstructive Surgeons [9] independently began working on residency training and the qualifications of specialists. As Korea became wealthier, those who could financially afford plastic surgery and had the leisure time started to pay more attention to their physical appearance [10]. In considering the growing influence of plastic surgery on society, it is urgent to establish standards of professionalism for health care experts. Moreover, it is necessary to establish a proper professional code of ethics. Therefore, the purpose of this research is to identify plastic surgeons' perception of professionalism, core values, and types of professionalism. Such information would provide the basis to build a model of professionalism to fulfill the duties of a plastic surgeon as a professional.

\section{METHODS}

This study targeted the 325 plastic surgery specialists and residents registered in the Korean Society of Plastic and Reconstructive Surgeons in 2012. Of these, 256 (78.8\%) were specialists, and $69(21.2 \%)$ were residents. Total respondents numbered 106 (32.6\%). Face-to-face and postal surveys were conducted with one respondent excluded from the final subjects due to an incomplete questionnaire.

The survey questions were designed by modifying a survey by the Royal Physician Society, 2007 [1]. The contents of our survey included four questions (Fig. 1A). The vocational assessment of the core values of professionalism was revised in accordance with the ten categories of medical career professionalism presented by Castellani and Hafferty [11]. They are autonomy, altruism, interpersonal competence, personal morality, professional dominance, technical competence, social contract, social justice, lifestyle, and commercialism and are evaluated on a 5-point scale. The survey of the core values is described in the following figure (Fig. 1B). The Cronbach's alpha value based on the collected surveys was 0.825 . The average of the ten category values was calculated, and the high values were set as the priority.

The type of professionalism was compared using the seven types of medical professionalism presented by Castellani and Hafferty [11]. Castellani classified these types according to the ten category values. In particular, the professionalism of specialists practicing at university hospitals and clinics, and then residents were compared. The collected values through the survey

\section{Fig. 1. Survey}

(A) Questions on the perception of professionalism. (B) Vocational assessment of the core values.
The following are survey questions as to the perception of the professionalism of Plastic Surgery.

1. Do you think your future as a plastic surgery specialist is positive?

a. Yes. Excellent b. Yes, Good c. No, concerned d. No, very concerned

2. Do you think your profession as a plastic surgeon is being threatened?

a. Yes b. No

3. How do you express your position as a plastic surgeon over the past 10 years?

The following are vocational assessment of the core values of professionalism.

5 point scale

1. Authority to strengthen discipline is necessary rather than external control over the internal problems of the group.

$\begin{array}{llllll}1 & 2 & 3 & 4 & 5\end{array}$

2. For the sake of patients, you may sacrifice your own personal interests.

3. Interaction between experts and cooperation led to the successful research result.

4. High morality is required for a fair judgment.

5. As an expert, you need to play a leading role in the decision-making on the matters of medicine

6. Professional work skills are needed including a variety of medical knowledge and technique to perform as a specialist.

7. Experts group should be exemplary through a sincere compliance to the law (tax payment) \begin{tabular}{l|l|l|l|l}
1 & 2 & 3 & 4 & 5
\end{tabular}

\begin{tabular}{l|l|l|l|l|}
1 & 2 & 3 & 4 & 5
\end{tabular}

\begin{tabular}{l|l|l|l|l}
1 & 2 & 3 & 4 & 5
\end{tabular}

\begin{tabular}{l|l|l|l|l}
1 & 2 & 3 & 4 & 5
\end{tabular}

\begin{tabular}{l|l|l|l|l}
1 & 2 & 3 & 4 & 5
\end{tabular}

\begin{tabular}{l|l|l|l|l}
1 & 2 & 3 & 4 & 5
\end{tabular} 
are listed in the order of the highest value. The most important rank and the least important rank category were evaluated by comparing them with the items in Castellani's seven categories. The subjects were divided into two groups of specialists and residents, and the differences between them were compared. The criteria for the specialist group was at least 10 years of experience as a specialist. For the resident group, they were divided into two groups as follows: low year for 1st and 2nd year, high year for $3 \mathrm{rd}$ and 4 th year. The proportions of each possible response to an item were obtained through frequency analysis. Using a Mann-Whitney U test method, the difference in the response of the resident group and the specialist group was compared. The SPSS ver. 17.0K (SPSS Inc., Chicago, IL, USA) of the program was used.

\section{RESULTS}

Of the respondents, $69.5 \%$ were in their 40 s $(37.1 \%)$ and $30 \mathrm{~s}$ (32.4\%). The gender of the subjects was mostly male, consisting of 98 subjects (93.3\%), and 7 female subjects (6.7\%). Clinics (61.0\%) and university hospitals (28.3\%) were the most common workplaces. In the case of the specialists except for the

\section{Fig. 2. General characteristics of the subjects}

(A) Age. (B) Gender. (C) Workplace. (D) Main expertise. (E) Resident grade. (F) Specialist career.

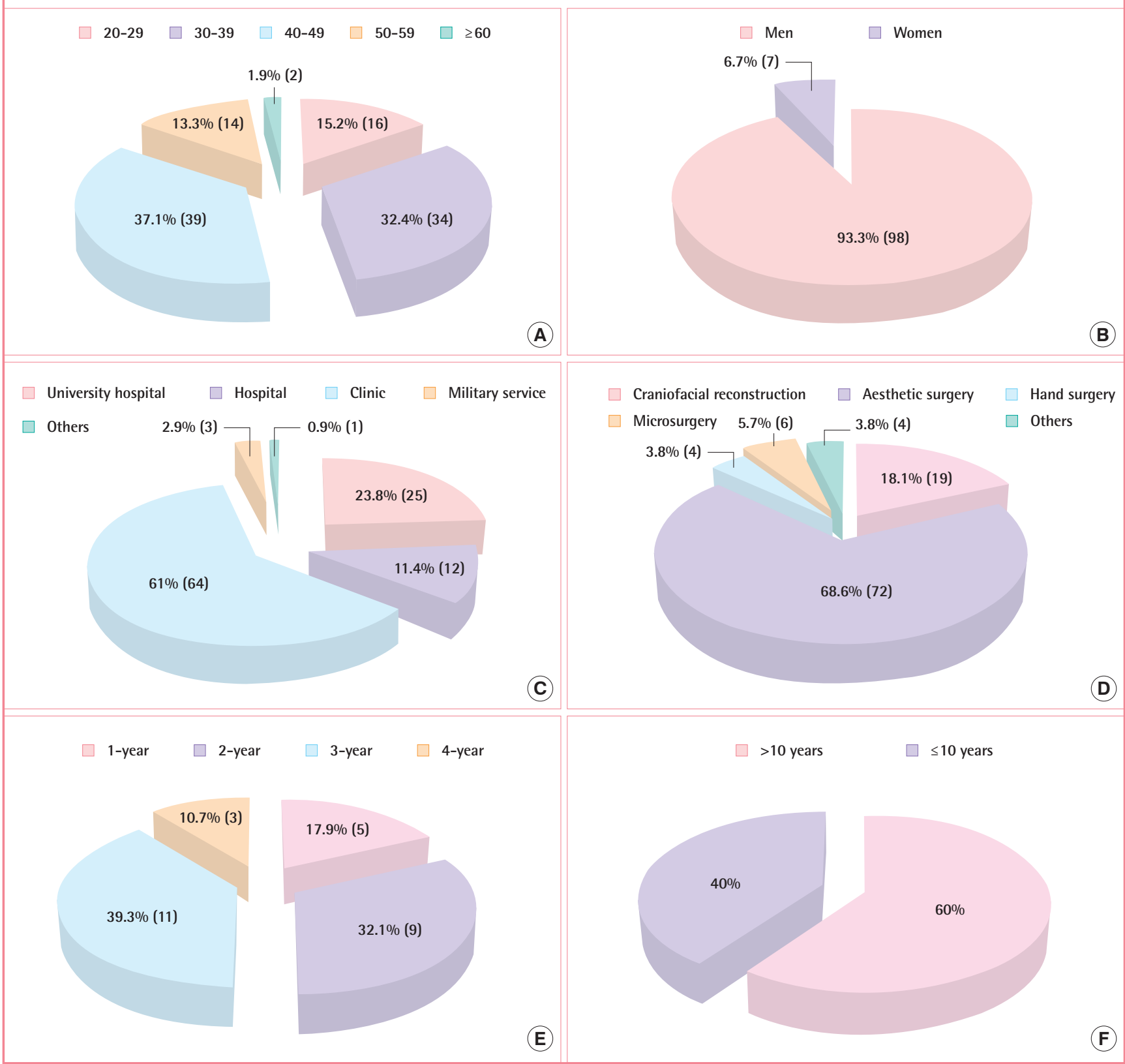


residents, aesthetic surgery was the major task performed in the workplace indicated by 72 respondents, with 19 for craniofacial reconstruction, 6 for microsurgery, 4 for hand surgery and 4 for other. The number of specialists with experience of less than 10 years was 31 (40.3\%), and those with experience of more than 11 years was 46 (59.7\%). The respondents to the survey were 77 specialists (73.3\%) and 28 residents (26.7\%) (Fig. 2).

A total of $90.5 \%$ of the respondents saw their future as a plastic surgeon as positive, which was higher than the negative response of $9.5 \%$. There was no difference between the responses of the residents and the specialists. The proportion of respondents considering the future of a plastic surgery specialist as being threatened was $77.1 \%$, and those who did not was $22.9 \%$. The proportion of negative responses for the leadership of the plas- tic surgery specialist in the medical field in the past 10 years was $28.6 \%$, and there was no difference between the group of residents and the specialists. The proportion of responses who viewed the reliability of plastic surgery specialists as declining was $48.6 \%$, and those who did not was $53.4 \%$. There was no statistically significant difference (Fig. 3 ).

According to the ten value items of medical professionalism presented by Castellani and Hafferty [11], the respondents indicated that "professional dominance" (4.58 pts) was the most important value item of the professionalism of plastic surgeons. The others were "autonomy" ( 4.45 pts), "life style" ( 4.34 pts), "commercialism" (4.31 pts), "technical competence" (4.25 pts), "personal morality" (4.21 pts), "social contract" (3.94 pts), "altruism" (3.84 pts), "interpersonal competence" (3.79 pts), and

Table 1. Mean score of the ten virtues of medical professionalism of plastic and reconstructive surgeons between specialists and residents

\begin{tabular}{|c|c|c|c|c|c|c|c|c|c|c|}
\hline \multirow{2}{*}{10 Virtues } & \multicolumn{4}{|c|}{ All subjects } & \multicolumn{3}{|c|}{ Specialist } & \multicolumn{3}{|c|}{ Residents } \\
\hline & Specialist & Resident & Total & P-value ${ }^{\text {a) }}$ & $>10 \mathrm{yr}$ & $\leq 10 \mathrm{yr}$ & P-value ${ }^{\text {a) }}$ & Low yr & High yr & P-value ${ }^{a)}$ \\
\hline Autonomy & 4.57 & 4.33 & 4.45 & 0.36 & 4.66 & 4.48 & 0.55 & 4.68 & 4.12 & 0.06 \\
\hline Altruismoa) & 4.12 & 3.56 & 3.84 & 0.03 & 4.03 & 4.15 & 0.58 & 3.34 & 3.62 & 0.29 \\
\hline Interpersonal competence & 3.81 & 3.77 & 3.79 & 0.85 & 3.88 & 3.77 & 0.69 & 3.65 & 3.84 & 0.51 \\
\hline Personal morality & 4.25 & 4.16 & 4.21 & 0.71 & 4.23 & 4.28 & 0.82 & 3.92 & 4.21 & 0.42 \\
\hline Professional dominance & 4.49 & 4.66 & 4.58 & 0.44 & 4.41 & 4.53 & 0.43 & 4.87 & 4.59 & 0.22 \\
\hline Technical competence & 4.15 & 4.35 & 4.25 & 0.35 & 4.09 & 4.18 & 0.66 & 4.21 & 4.42 & 0.38 \\
\hline Social contract & 3.75 & 4.12 & 3.94 & 0.08 & 3.65 & 3.97 & 0.31 & 3.96 & 4.29 & 0.37 \\
\hline Social justice & 3.68 & 3.53 & 3.61 & 0.39 & 3.51 & 3.74 & 0.38 & 3.47 & 3.59 & 0.54 \\
\hline Lifestyle & 4.27 & 4.41 & 4.34 & 0.56 & 4.26 & 4.35 & 0.76 & 4.38 & 4.53 & 0.35 \\
\hline Commercialism & 4.34 & 4.28 & 4.31 & 0.92 & 4.28 & 4.39 & 0.65 & 4.14 & 4.36 & 0.41 \\
\hline
\end{tabular}

Table 2. Ranking by priority of the ten virtues of medical professionalism of plastic and reconstructive surgeons

\begin{tabular}{|c|c|c|c|c|c|c|c|}
\hline \multirow{2}{*}{ Ranking } & \multicolumn{3}{|c|}{ All subjects } & \multicolumn{2}{|c|}{ Specialist } & \multicolumn{2}{|c|}{ Resident } \\
\hline & Specialist & Resident & Total & $>10 \mathrm{yr}$ & $\leq 10 \mathrm{yr}$ & Low yr & High yr \\
\hline \multirow[t]{4}{*}{ Highest } & Autonomy & $\begin{array}{l}\text { Professional } \\
\text { dominance }\end{array}$ & $\begin{array}{l}\text { Professional } \\
\text { dominance }\end{array}$ & Autonomy & $\begin{array}{l}\text { Professional } \\
\text { dominance }\end{array}$ & $\begin{array}{l}\text { Professional } \\
\text { dominance }\end{array}$ & $\begin{array}{l}\text { Professional } \\
\text { dominance }\end{array}$ \\
\hline & $\begin{array}{l}\text { Professional } \\
\text { dominance }\end{array}$ & Lifestyle & Autonomy & $\begin{array}{l}\text { Professional } \\
\text { dominance }\end{array}$ & Autonomy & Autonomy & Lifestyle \\
\hline & Commercialism & $\begin{array}{l}\text { Technical } \\
\text { competence }\end{array}$ & Lifestyle & Commercialism & Commercialism & Lifestyle & $\begin{array}{l}\text { Technical } \\
\text { competence }\end{array}$ \\
\hline & Lifestyle & Autonomy & Commercialism & Lifestyle & Lifestyle & $\begin{array}{l}\text { Technical } \\
\text { competence }\end{array}$ & Commercialism \\
\hline \multirow[t]{3}{*}{ Middle } & Personal morality & Commercialism & $\begin{array}{l}\text { Technical } \\
\text { competence }\end{array}$ & Personal morality & Personal morality & Commercialism & Social contract \\
\hline & $\begin{array}{l}\text { Technical } \\
\text { competence }\end{array}$ & Personal morality & Personal morality & $\begin{array}{l}\text { Technical } \\
\text { competence }\end{array}$ & $\begin{array}{l}\text { Technical } \\
\text { competence }\end{array}$ & Social contract & Personal morality \\
\hline & Altruism & Social contract & Social contract & Altruism & Altruism & Personal morality & Autonomy \\
\hline \multirow[t]{3}{*}{ Lowest } & $\begin{array}{l}\text { Interpersonal } \\
\text { competence }\end{array}$ & $\begin{array}{l}\text { Interpersonal } \\
\text { competence }\end{array}$ & Altruism & $\begin{array}{l}\text { Interpersonal } \\
\text { competence }\end{array}$ & Social contract & $\begin{array}{l}\text { Interpersonal } \\
\text { competence }\end{array}$ & $\begin{array}{l}\text { Interpersonal } \\
\text { competence }\end{array}$ \\
\hline & Social contract & Altruism & $\begin{array}{l}\text { Interpersonal } \\
\text { competence }\end{array}$ & Social contract & $\begin{array}{l}\text { Interpersonal } \\
\text { competence }\end{array}$ & Social justice & Altruism \\
\hline & Social justice & Social justice & Social justice & Social justice & Social justice & Altruism & Social justice \\
\hline
\end{tabular}


Fig. 3. Perception of professionalism among specialists and residents

(A) Survey question 1. (B) Survey question 2. (C) Survey question 3. (D) Survey question 4.

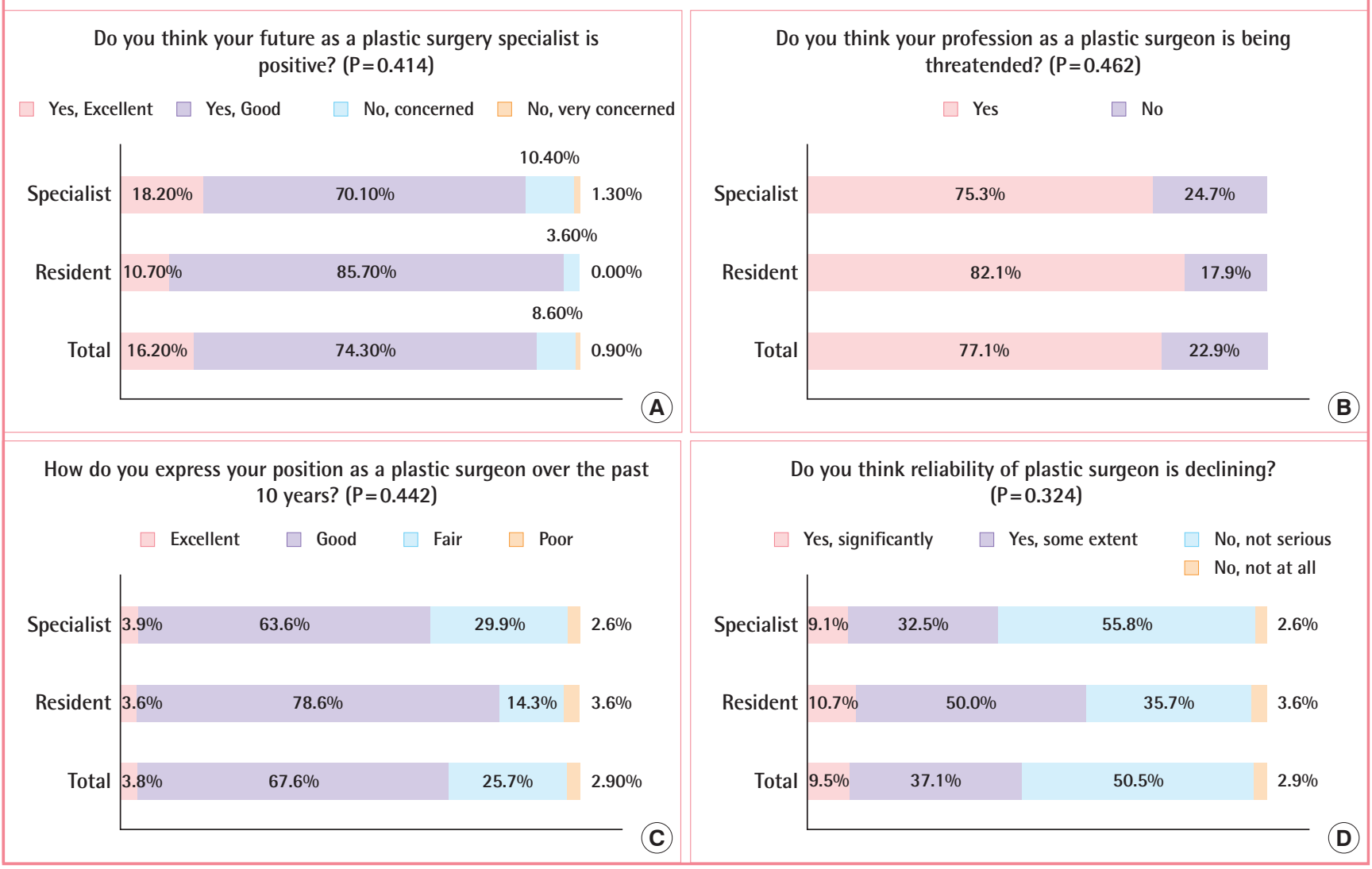

Table 3. Comparison of professionalism type among the three groups

\begin{tabular}{|lccc|}
\hline \multirow{2}{*}{ Professionalism } & \multicolumn{3}{c|}{ Subjects } \\
\cline { 2 - 4 } & $\begin{array}{c}\text { University } \\
\text { hospital }\end{array}$ & Clinic & Resident \\
\hline Type & Academic & Entrepreneurial & Entrepreneurial \\
Feature & - Academic work & - Practice medicine as a business \\
& $\begin{array}{c}\text { - High rank on } \\
\text { altruism }\end{array}$ & - High rank on commercialism \\
\hline
\end{tabular}

“social justice" (3.61 pts), respectively (Table 1). To summarize the importance of the value items of medical professionalism, there was no significant difference in the comparison of the two groups, one with 10 and the other with less than 10 years of experience. They evaluated "autonomy," "professional dominance," and "commercialism" as important. In the resident group comparing the low and high years, the low year group considered "professional dominance," "autonomy," and "life style" to be more important. The high-year group considered "professional dominance," "life style", and "technical competence" to be more important. There was no statistically significant difference between the groups (Table 1).
Although the plastic surgeon cannot be exactly matched with the type of medical professionalism suggested by Castellani and Hafferty [11], it was most similar to the entrepreneurial type that views medicine as an enterprise. In the case of the residents, it was similar to the entrepreneurial type in that they regarded "professional dominance," "life style," and "technical competence" as important and evaluated "altruism" and "social justice" poorly (Table 2). In addition, university specialists at hospitals and clinics indicated academic and entrepreneurial types, respectively (Table 3 ).

\section{DISCUSSION}

The fierce competition, commercialization, and industrialization of medicine within the medical field has increased the pursuit of individual interests over of the needs of patients. Also, the entrepreneurial approach of some medical professionals has been highlighted as undermining basic values such as honesty and morality. Therefore, the establishment of role models that may function harmoniously in a society is very important as it may appropriately counteract conflict [12-14]. As all of the subjects evaluated "professional dominance," "autonomy," "life style," and 
"commercialism" highly as value items, while the traditionally important value items for professionalism, "altruism" was poorly assessed implies that a plastic surgeon's lifestyle is generally regarded as a higher priority than altruism. A comparison of the priorities of residents and specialists showed similarities. However, the result of "altruism" yielded a significant difference between the two groups. In the group of residents, "lifestyle" (4.41 pts) was the second priority, reflecting the values of a younger generation who are more likely to place a priority on their and their family's lifestyle. The specialist group showed that there was no significant difference, while a comparison of residents by year did not show a statistically significant difference. The low year group assessed "professional dominance," "autonomy," and "lifestyle" to be important. The high year group put greater importance on "professional dominance," "lifestyle", and "technical competence" (Tables 1,2).

The plastic surgeons did not match any category of professionalism presented by Castellani and Hafferty [11]. Although it can be interpreted as a result of differences between Western culture and the diversity of physicians in different countries, the uniqueness of the plastic surgeon's field played a role as well. Although there were similarities with entrepreneurial or empirical types, it did not match completely. Specialists of university hospitals and clinics showed that their type is close to "academic" and "entrepreneurial," respectively (Table 3 ). The plastic surgery residents group considered "professional dominance," "life style," and "technical competence" to be important and evaluated "altruism" and "social justice" poorly. This indicated that they have similar characteristics as the "entrepreneurial type" (Tables 2, 3). The academic type is usually found in physicians working in academic medical centers, medical schools, and related medical organizations. While they rank altruism high and commercialism low, they do not place much stock in issues of autonomy or professional dominance. The entrepreneurial type tends to regard medicine as a business and shows interest in yielding a high profit. This group is characteristic of the type of doctor who sells beauty products or engages in cosmetic surgery [11].

The professionalism crisis in the field of plastic surgery in Korea is intensifying due to growing awareness of patient's rights as well as unreasonable regulations and policies that infringe and restrict the autonomy of doctors. The commercialization caused by the increase in the number of doctors leading to overcompetition in the medical society is also to blame [15]. Also, poorly defined roles of specialists due to the short history of the specialist system is presumed to be one of the main factors that have led to this crisis. In order to overcome the crisis of professionalism in plastic surgery, excellence, humanism, accountability, and altruism should be pursued. Independence from the domination of the market as well as the state must also be obtained [15]. In addition, the Korean Society of Plastic and Reconstructive Surgeons should develop a code of ethics for the professionalism of plastic surgeons. Also, they should endeavor to produce plastic surgery specialists with a higher level of knowledge and morality. Efforts must also be made to prevent their unique professional area from encroachment by the developing cosmetic and reconstructive fields.

In general, altruism is considered important as a necessary core value to maintain professionalism, but it is underrated by the participants in this study. This may be attributed to the high emphasis on the excellence, professional knowledge, and skills in the field of plastic surgery during the process of putting effort into differentiatiating roles, task performance, and establishing identity. However, the tendency to underestimate the core value of altruism cannot be ignored, and therefore further study should be conducted. Moreover, the Korean society of Plastic and Reconstructive Surgeons should provide opportunities to expand the competencies of professionals by carrying out appropriate professionalism training programs for plastic surgeons [16]. In particular, training programs to enhance skills and competencies in accordance with the principles of professionalism should be introduced [17].

The limitations of this study may have been the relatively high percentage of specialist opinions. Second, the number of subjects working in private clinics was higher, which may have affected the interpretation of the results. Third, further review is necessary as to the adoptability of Castellani's core values and types to explain the current environment for plastic surgery in Korea. However, the significance of this study is that this is the first research to be conducted targeting the registered specialists and residents since the founding of the Korean Society for Plastic and Reconstructive Surgeons in 1966. This work serves as a primary work to increase our understanding of the role of plastic surgeons by identifying the types of professionalism and determining the appropriate code of ethics.

\section{REFERENCES}

1. Miles SH. The Hippocratic oath and the ethics of medicine. New York: Oxford University Press; 2004.

2. Cruess RL, Cruess SR. Teaching medicine as a profession in the service of healing. Acad Med 1997;72:941-52.

3. Moore DA, Loewenstein G. Self-interest, automaticity and the psychology of conflict of interest. Soc Justice Res 2004; 17:189-202.

4. American Society of Plastic Surgeons [Internet]. Arlington Heights, IL: American Society of Plastic Surgeons; c2012 
[cited 2013 Feb 4]. Availble from: http://www.plasticsurgery.org/Documents/ByLaws/Code_of_Ethics_March12. pdf.

5. Sullivan W. Work and integrity: the crisis and promise of professionalism in North America. New York: Harper Collins; 1995.

6. Yeo IS, Park Y, Lee KL, et al. A history of medical license in Korea. Korean J Med Hist 2002;11:137-53.

7. ParkJY. Changes of medical professionalism in Korea. Korea J Sociol 1993;27:219-44.

8. Cheong YS. Medical professionalism and clinical autonomy in Korea. Korean J Med Ethics 2004;7:141-50.

9. History of the Korean Society of Plastic and Reconstrucive Surgeons [Internet]. Seoul: The Korean Society of Plastic and Reconstructive Surgeons; [cited 2013 Feb 4]. Available from: http://www.plasticsurgery.or.kr/php/kor/society/ society02_01.php.

10. The Korean Society for Aesthetic Plastic Surgery [Internet]. Seoul: The Korean Society for Aesthetic plastic surgery; c2011 [cited 2013 Feb 4]. Available from: http://www. ksaps.or.kr/bbs/addon.php?addon_id=a_01.

11. Castellani B, Hafferty FW. The complexities of medical professionalism. In: Wear D, Aultman JM, editors. Professionalism in medicine: critical perspectives. New York: Springer; 2006. p. 3-23.

12. Hwang EY, Yang EB. The attributes and practical principle of medical professionalism. Korean Med Educ Rev 2010;12: 9-22.

13. Aris $S$, Henrique NR, Ivo P. Ethical issue in plastic and reconstructive surgery. Aesthetic Plast Surg 2011;35:262-7.

14. Zbar RI, Taylor LD, Canady JW. Ethical issues for the plastic surgeon in a tumultuous health care system: dissecting the anatomy of a decision. Plast Reconstr Surg 2008; 122:1245-52.

15. Oh YH. Changes and prospect of health care in 2011. Health Welf Policy Forum 2011;171:14-23.

16. Murray JE. On ethics and the training of the plastic surgeon. Plast Reconstr Surg 1978;61:270-1.

17. May JW Jr. The honor and responsibility of teaching in plastic surgery. Plast Reconstr Surg 1991;88:869-73. 